\title{
KNOWLEDGE AND PRACTICE ON SELECTED ASPECTS OF POSTNATAL CARE AMONG POSTNATAL MOTHERS
}

\author{
Pradhan (Thaiba) A ${ }^{1}$, Rani $\mathrm{U}^{2}$
}

ABSTRACT

\section{INTRODUCTION:}

Maternal mortality is higher in women living in rural areas and among poorer communities. Young adolescents face a higher risk of complications and death as a result of pregnancy than other women. Skilled care before, during and after childbirth can save the lives of women and newborn babies. ${ }^{1}$ Only a small proportion of women in developing countriesless than $30 \%$ receive adequate postpartum care. In very poor countries and regions as few as $5 \%$ of who receive such care. A large proportion of maternal deaths occur during the first 6 weeks after delivery, and postpartum care might help to prevent many of these deaths. In developed countries, $90 \%$ of new mothers receive postpartum care. ${ }^{2}$

\section{MATERIALS \& METHODS:}

A descriptive approach with descriptive correlation research design was used to assess the knowledge and practice on selected aspects of postnatal care among postnatal mothers. The study was carried out in Banashankari Referral Hospital, Bangalore. The purposive sampling technique was used to select the 60 samples of postnatal mothers. The collected data were analyzed by using descriptive and inferential statistics.

\section{RESULTS:}

Thirty Three (55\%) respondents were having moderately adequate knowledge regarding selected aspects of postnatal care, $24(40 \%)$ were having inadequate knowledge and only $03(05 \%)$ of respondents had adequate knowledge out of 60 samples. The level of practice was out of 60 respondents, $29(48.33 \%)$ respondents were having inadequate practices, $26(43.33 \%)$ were having moderately adequate practices and only $05(08.34 \%)$ of them had adequate practices on selected aspects of postnatal care.

\section{CONCLUSION:}

The findings of the study conclude that the postnatal mothers had moderately adequate knowledge and practices on selected aspects of postnatal care. The study suggests that the postnatal mothers require educational instructions for improving the knowledge and practice.

Key words: Postnatal mothers, knowledge, practice, selected aspects, postnatal care

1. Lecturer, Sanjeevani College of Medical Sciences, Butwal, Nepal

2. Professor and HOD, Department of Obestetric and gynecological Nursing, Hillside College of Nursing, Bangalore, Karnataka

\author{
For Correspondence \\ Ms. Anupama Pradhan (Thaiba) \\ Lecturer \\ Sanjeevani College of Medical Sciences, \\ Butwal, Nepal \\ E-mail: anupamapradhan12@gmail.com
}




\section{INTRODUCTION}

The postnatal period or puerperium is a period of adjustment after pregnancy when the anatomic and physiological changes of pregnancy are reversed and body returns to the normal state. This period starts as soon as the placenta is expelled and extends up to the period of six weeks. During this time, the women recover from the stresses of pregnancy and delivery. The requirements during this period are nutritious diet, personal hygiene, postnatal exercises, breast feeding, family planning and immunization to the baby.

Postnatal care is the care given to the mother after delivery, up to 6 weeks period, during which reproductive organs return to normal size, shape and optimum health is restored. ${ }^{4}$

The WHO estimates that 150 million deliveries occur annually,Worldwide, every minute of every day, one woman dies of pregnancy related complications. Nearly 6, 00,000 women die each year; of these $99 \%$ of deaths occur in developing countries. Every single woman who dies, 30 women develop life long illness and injuries related to pregnancy and childbirth.In India, every five minutes, one woman dies from complications related to pregnancy and childbirth. This adds up to a total of 1,21,000 women per years.15\% of the women develop life threatening complications. $65 \%$ of deliveries are conducted at home. $41 \%$ of the women have skilled attendants to assist in childbirth.

A descriptive study was conducted in 2005 at Mangalore, India to assess the knowledge, attitude and practice of employed mothers about Breastfeeding. Data was collected from 60 mothers. The study revealed that $86.66 \%$ of the respondents knew that colostrum protects the child from infection, $46.67 \%$ of the subjects had knowledge that breast feeding should be initiated within 30 minutes after birth. $36.67 \%$ of the subjects had expressed that breast feeding should be on demand, $48.33 \%$ of the subjects believed that they will spoil their baby if they pick them up and feed every time they cry, $20.27 \%$ of the sample believed that eating extra food during lactation will spoil one's figure. ${ }^{6}$

\section{MATERIALS \& METHODS}

To assess the knowledge and practice on selected aspects of postnatal care among postnatal mothers in selected maternity hospital, the investigator has selected descriptive approach with descriptive correlation research design \& structured interview schedule and practice checklist were used to collect data. The sample consisted of 60 subjects were selected by non probability purposive sampling technique. Preparation of the tool was done based on review of literature, content validation and establishment of reliability. The content validity was established by item analysis of the tool by experts in the field of Obstetric and Gynecological nursing. To ensure the validity of the tool, the tool was given to 08 experts in the field OBG and OBG nursing. Interview schedule and practice checklist were prepared based on the review of literature, after content validity and suggestions from the experts. The reliability of the tool was tested by using split half method. Statistical test coefficient of correlation was used to find out the reliability. The reliability Karl Pearson coefficient of correlation was $\mathrm{r}=0.89$ for knowledge and $\mathrm{r}=0.79$ for practice. The investigator conducted the pilot study in Hillside Hospital from $13^{\text {th }}$ to $21^{\text {st }}$ Jan 2012 to confirm the feasibility of conducting the main study. The study was conducted with 10 samples. The proposed study was conducted after the approval of research Committee of Hillside College of Nursing. The data for main study was collected from $5^{\text {th }}$ March to $4^{\text {th }}$ April 2012; the samples were 60 Postnatal mothers of Banashankari Referral Hospital at Bangalore. The obtained data was analyzed by using both descriptive and inferential statistics. The analysis was based on the objectives and hypothesis of the study. Frequency and percentage were used to analyze the baseline proforma. Frequency, percentage, mean, standard deviation, mean percentage score were use to analyze the data and Correlation coefficient were used to correlate the knowledge and practices of postnatal mothers. Chi-square test was done to find out the association between the levels of knowledge and practices with their selected demographic variables of postnatal mothers.

\section{RESULTS}

The analysis and interpretation of data collected to assess the knowledge and practice on selected aspects of postnatal care among postnatal mothers in selected maternity hospital. Analysis of data was a process by which quantitative information is reduced, organized, summarized, evaluated, interpreted and communicated in a meaningful way. The results were computed by using descriptive and inferential statistics based on the objectives of the study. The objectives of this study were to assess the level of knowledge on selected aspects of postnatal care among postnatal mothers, to assess the level of practices on selected aspects of postnatal care among postnatal mothers, to find out the correlation between knowledge score and practice score on selected aspects of postnatal care among postnatal mothers, to find out the association between knowledge score and practice score on selected aspects of postnatal care among postnatal mothers with selected demographic variables. The data were presented under the subjects based on demographic variables, level of 
knowledge and practice on selected aspects of postnatal care, Correlation between knowledge score and practice score, association between knowledge score and practice score with selected demographic variables.

\section{Distribution of subjects based on demographic variables:}

Majority $46(76.7 \%)$ of the postnatal mothers belong to age group of 25-29 years. $32(53.33 \%)$ of postnatal mothers were Hindus. $39(65 \%)$ of postnatal mothers belonged to nuclear family. The majority of the postnatal mothers $34(56.67 \%)$ had higher secondary education. $16(26.67 \%)$ of the postnatal mothers were housewives. $53(88.33 \%)$ of postnatal mothers reside at urban area. $26(43.33 \%)$ of postnatal mothers had an income of Rs.4001 to Rs.5000 per month. 42(70\%) of postnatal mothers were primipara. $54(90 \%)$ of postnatal mothers were registered, and $21(35 \%)$ had received the information from mass media.

\section{Findings related to level of knowledge and practice}

Out of 60 respondents, 33(55\%) had moderately adequate knowledge regarding selected aspects of postnatal care, $24(40 \%)$ had inadequate knowledge and only $03(05 \%)$ had adequate knowledge. In the aspect of practice, 29(48.33\%) had inadequate practices regarding selected aspects of postnatal care, $26(43.33 \%)$ had moderately adequate practices and only $05(08.34 \%)$ of them had adequate practices. The mean percentage level of knowledge of postnatal mothers on selected aspects of postnatal care was $50.23 \%$ and the mean level was 17.58 with standard deviation of 2.6. The mean percentage level of practices of postnatal mothers on selected aspects of postnatal care was $52 \%$, the mean was 10.40 with standard deviation of 2.1 .

The overall mean percentage level of knowledge of postnatal mothers on selected aspects of postnatal care was $50.23 \%$, the mean was 17.58 with standard deviation of 2.6. In the aspect of general information, the mean percentage was $47.50 \%$ with mean and SD of $1.9 \pm 0.64$ whereas, in diet aspect, the mean percentage was $49 \%$ with mean and SD of $4.9 \pm 1.34$. The personal hygiene, mean percentage was $51.67 \%$ with mean and SD of $3.1 \pm 0.83$ and postnatal exercises' mean percentage was $54.29 \%$ with mean and SD of $3.8 \pm 0.82$. In aspect of breast feeding mean percentage was $47.5 \%$ with mean and SD of $3.8 \pm 0.97$. the overall mean percentage level of practices of postnatal mothers on selected aspects of postnatal care was $52 \%$, the mean was 10.40 with standard deviation of 2.1 . In the aspect of diet, the mean percentage was $53.33 \%$ with mean and $\mathrm{SD}$ of $1.6 \pm 0.70$ whereas, personal hygiene mean percentage was $40.00 \%$ with mean and SD of $2.4 \pm 0.61$ and postnatal exercises' mean percentage was $72.50 \%$ with mean and SD of $2.9 \pm 0.74$. However, breast feeding mean percentage was $47.14 \%$ with mean and SD of $3.3 \pm 0.96$.

Findings related to Correlation between the knowledge and practice

The correlation coefficient obtained was $r=0.84$. This value indicates that there was a positive correlation between level of knowledge and practice of postnatal mothers regarding selected aspects of postnatal care.

\section{HYPOTHESIS TESTING}

$\mathrm{H}_{1}$ : There is a significant correlation between knowledge scoreand practice score of postnatal mothers regarding $\mathrm{s}$ elected aspect of postnatal care.

The correlation coefficient obtained was $r=0.84$. This value indicates that there was a positive correlation between level of knowledge and practice. Hence the stated hypothesis is accepted

$\mathrm{H}_{2}$ : There is a significant association between knowledge score with selected demographic variables of postnatal mothers.

The obtained chi-square value shows that there was a significant association between the level of knowledge and type of family $\left(\mathbf{x}^{2}=3.98, \mathrm{df}=1\right)$, but it didn't show any significant association between other demographic variables of postnatal mothers. Hence the stated hypothesis is accepted only for the demographic variable; type of family.

$\mathrm{H}_{3}$ :There is a significant association between practice score with selected demographic variables of postnatal mothers. The obtained chi-square value shows that there was a significant association between level of practice and the parity $\left(\chi^{2}=3.92, \mathrm{df}=1, \mathrm{P}<0.05\right)$ but it didn't show any significant association with other demographic variables of postnatal mothers. Hence the stated hypothesis is accepted only for the demographic variable; parity.

\section{DISCUSSION}

The statistical analysis showed that out of 60 respondents, $33(55 \%)$ had moderately adequate knowledge regarding selected aspects of postnatal care, $24(40 \%)$ had inadequate knowledge and only 03(05\%) respondents had adequate knowledge. The mean percentage level of knowledge of postnatal mothers on selected aspects of postnatal care was $50.23 \%$, the mean was 17.58 with standard deviation of 2.6.

The above findings are supported by a descriptive study which was conducted to assess the knowledge and practice on 
selected aspects of postnatal care among postnatal mothers in selected hospitals at Banagalore in 2004. The sample size was 70 postnatal mothers with 35 primiparous and 35 multiparous. This study reveals that $27 \%$ of the mothers had low level of knowledge, 39\% had medium and 34\% had high level of knowledge. The educated mothers possess better knowledge compared to the uneducated. The findings of the study reveal that postnatal mothers had highest mean percentage of knowledge score in the aspect of postnatal diet but less on postnatal exercises.

Out of 60 respondents, 29(48.33\%) had inadequate practice regarding selected aspects of postnatal care, 26(43.33\%) had moderately adequate practice and only $05(08.33 \%)$ of them had adequate practice. The mean percentage level of practices of postnatal mothers on selected aspects of postnatal care was 52 , the mean was 10.40 with standard deviation of 2.1 .

The above findings are supported by the study which was conducted in 2009 at Mangalore ${ }^{10}$ to assess the postnatal care practices of a selected ethnic group. A semi structured openended interview schedule was used. The study revealed that all $100 \%$ did not know what type of food they should take and when they could start normal diet. $86.67 \%$ of them restricted the quantity of fluid intake, $60 \%$ of them did not know about the importance of ambulation and exercise, 33.3\% believed that early ambulation and exercises caused excessive bleeding and prolapsed of the uterus. It was found that majority $(60 \%)$ of the mothers did not know when they should go for follow up visits. Majority of them (53.44\%) initiated breastfeeding only after 3 days. Only $46.67 \%$ of them fed the babies with colostrums. In caring for the umbilical cord, application of turmeric powder was the most widely prevalent practice among this group (53.33\%) applying saliva, (3.33\%) breast milk or coconut oil $(3.33 \%)$. The study concludes that the mothers were having lack of knowledge and practice on breast feeding. ${ }^{8}$

The correlation coefficient between level of knowledge and practices of postnatal mothers on selected aspects of postnatal care was $r=0.84$. This value indicates that there was a positive correlation between level of knowledge and practice of postnatal mothers regarding selected aspects of postnatal care. The above findings are supported by a quasi-experimental study which was conducted to assess the effectiveness of structured teaching programme on postnatal exercise of mothers in postnatal wards of selected maternity centers at Madurai in 2002. ${ }^{9}$ Systematic sampling technique was used to select 40 postnatal mothers as sample. A structured interview schedule was used to assess the knowledge of mothers and practice checklist was used to assess the practice of mothers regarding postnatal exercise. They were given a pre-test and post-test. The findings of the study showed that there was significant different in post test knowledge score of the experimental group $(\mathrm{t}=31.78,<0.01)$ and there was a positive correlation $(\mathrm{r}=0.86)$ between knowledge and practice. The study concludes that there was effectiveness of the structured teaching programme on postnatal care.

The obtained chi-square value shows that there was a significant association between level of practice and parity $\left(\chi^{2}\right.$ $=3.92, \mathrm{df}=1, \mathrm{P}<0.05)$, but it didn't show any significant association with other demographic variables of postnatal mothers.

The above findings are supported by the similar study which was conducted in $2009^{10}$ to find out the existing level of knowledge of mothers regarding personal hygienic measures. The result shown that below 30yrs of mothers obtained higher mean $(\%)$ percentage scores are $(56.4 \%)$ than those of older age mothers $(47.4 \%)$. The primipara scored higher mean $\%$ score $(56.4 \%)$ as compared to multipara (55.4\%). Mothers with a high level of education obtained high mean percentage score $(66.0 \%)$ than those with a low level of education $(40.6 \%)$. Professional mothers scored higher mean percentage score $(68.8 \%)$ than those of house wives $(54.6 \%)$. High level of income mothers obtained a higher mean percentage score (73.8\%) as compared to the low level income mothers $(28.3 \%)$. The study further revealed that joint family scored higher mean percentage score $(62.2 \%)$ than those of nuclear family mothers $(49.5 \%)$. The findings of the study suggest that the mothers were having lack of knowledge and the urban mothers were having good knowledge. ${ }^{10}$

\section{CONCLUSION}

The statistical analysis showed that out of 60 respondents, $33(55 \%)$ respondents were having moderately adequate knowledge regarding selected aspects of postnatal care $24(40 \%)$ were having inadequate knowledge and only $03(05 \%)$ of respondents had adequate knowledge. In aspect of practice, 29(48.33\%) respondents were having inadequate practices regarding selected aspects of postnatal care, $26(43.33 \%)$ were having moderately adequate and only $05(08.34 \%)$ of them had adequate practices.

\section{RECOMMENDATIONS}

The study may be repeated by taking a large sample of postnatal mothers. A comparative study to assess the knowledge and practice of rural and urban postnatal mothers' on selected aspects of postnatal care. Educational 
interventional studies such as structured teaching programme, video assisting program or self instructional module can be undertaken inorder to enhance the level of knowledge of postnatal mothers.

\section{REFERENCES}

1. WHO Fact Sheets; 2015. Available on: http://www.who.int mediacentre/factsheets/fs348/en/ Retrived on : $2^{\text {nd }}$ Sept. 2016

2. Manneh \& Fadinding. Assessment of knowledge, attitude and practice of primary health care workers in postpartum care in the North Bank East Division of the Gambia, Masteroppgave, University of Oslo;2013. Available on: https://www.duo.uio.no/handle/ 10852/30088? show $=$ full Retrived on : $2^{\text {nd }}$ Sept. 2016.

3. Park K. Textbook of Preventive and Social Medicine. $23^{\text {rd }}$ Ed (2015) Jabalpur: Banarasidas Bhanot Publishers.

4. Helen Varney. Nurse Midwifery. Boston: Joones and Barlett Publication; 2006.

5. WHO. Media Centre. Maternal mortality, Fact sheet No.348. May 2012. Available from URL http://http://www.who.int/ mediacentre/factsheets/fs348/en/index.html.

6. Rinda John. Knowledge, attitude and practice of employed mothers about breastfeeding. The nursing journal of India. 2005;4:85-86.
7. Krishnapriya G. A study to assess the knowledge and practice on selected aspects of postnatal care among postnatal mothers in a selected hospital Bangalore, unpublished M.Sc. Nursing thesis submitted to Rajiv Gandhi University of Health Sciences, Bangalore, Karnataka; 2004.

8. Rose Mary. A study to identify the postnatal care practices of a selected ethnic group with a view to propose guidelines for health teaching, unpublished M. Sc Nursing thesis submitted to Rajiv Gandhi University of health Sciences, Bangalore, Karnataka 2010 .

9. Latha M. A study to assess the effectiveness of STP on postnatal exercise of mothers in postnatal wards of selected maternity center in Madhurai (Unpublished master Thesis) Dr. MGR University of Chennai; 2002

10. Singh Maharban. A descriptive study to assess the existing level of knowledge of mothers regarding personal hygienic measures in selected community, Mangalore. Unpublished M.Sc. Nursing thesis submitted to Rajiv Gandhi University of Health Sciences, Bangalore, Karnataka; 2009. 